\title{
Pitch-Pattern Diffusion of Generational Tone Change in North Kyungsang Korean English Loanwords
}

\author{
Young Hwang ${ }^{\dagger}$ \& Stuart Davis \\ Indiana University
}

\begin{abstract}
North Kyungsang (NK) Korean is a pitch accent language that uses both high and low tones. NK Korean permits only one accented syllable in a single prosodic word; therefore, if an accented stem is combined with an accented suffix, one of the underlying accents must be deleted. According to traditional observations, NK English loanwords always maintain their stem accent, unlike NK native words. However, our recent observations reveal that this unique loanword pattern seems to be changing, especially among the younger generations. To determine the existence of this suffixal tonal change, a production task was conducted with younger and older speakers of NK Korean. The results reveal that a pitch-pattern diffusion is in progress across the board in final accented NK English loanwords when combined with an accented suffix. Such loanwords seem to be losing their unique tone patterns and nativizing their suffixal accent. Although the diffusion is occurring in both younger and older speakers, the degree of diffusion differs and is quite patterned, based on the speakers' age as well as the number of syllables and syllable structure of the words.
\end{abstract}

Keywords: North Kyungsang Korean, pitch-pattern diffusion, generational tone change

\section{Introduction}

North Kyungsang (NK) Korean, a dialect spoken in the northern part of the southeast region of Korea, has preserved a lexical pitch accent system from Middle Korean (15-16 centuries) (Ramsey 1975; I-S Lee and Ramsey 2000; Kenstowicz et al. 2008), and uses (H)igh and (L)ow tones to distinguish words (G-R Kim 1988; Y-H Chung 1991; N-J Kim 1997; J-H Jun et al. 2006; Kenstowicz and H-S Sohn 2001). In the NK native vocabulary, the accented high tone is assigned lexically and its position in the word is generally unpredictable (G-R Kim 1988; Y-H Chung 1991; N-J Kim 1997). However, unlike native words, the assignment of accent to English loanwords is sensitive to moraic structure and largely predictable in terms

\footnotetext{
† Corresponding author: hwang24@indiana.edu
} 
of syllable weight (M Kim 1997; Kenstowicz and H-S Sohn 2001; Y-H Chung 2002; J-S Kim 2009; Davis 2010).

The difference between NK native words and English loanwords is further seen in the pattern of accentuation when a suffix is added. Since NK Korean allows only one accent in a single prosodic word [stem+suffix], if an accented stem is combined with an accented suffix, one of the accents must be deleted. When the two underlying accents are not adjacent to each other, NK native words and English loanwords both retain the stem accent. Yet, when the underlying accents are next to each other and an accent clash occurs, NK native words and English loanwords exhibit distinct accentuation patterns: For NK native words, the stem loses its accent and the suffixal accent is maintained (e.g. parám (LH) 'wind' + - $-t^{h}$ ' $\rightarrow$ param-t. ${ }^{h}$ ' $\mathrm{r} \wedge m$ (LL-HL)), whereas the stem accent is retained for NK English

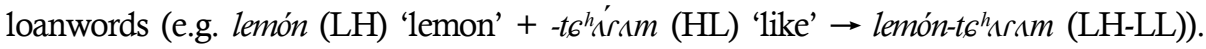
(Note that $\mathrm{L}$ indicates low tone and $\mathrm{H}$ indicates high tone; the high tone is normally associated with the accented syllable.) Consequently, English loanwords never yield their accent to suffixes (M Kim 1997; Kenstowicz and H-S Sohn 2001).

However, this observation is based on NK Korean as spoken in the 1990s and earlier, by a now older generation of speakers. The authors' recent observation reveals that the traditional loanword tone patterns seem to be nativized especially among younger generations and that this change has not been previously reported. Therefore, this study aims to track the tone pattern change occurring in NK English loanwords by answering the following three research questions: (1) Is the tone pattern change really in progress in NK English loanwords? (2) If it is, are there any social or linguistic factors that affect the degree of the change? (Two social factors, age and gender, and two linguistic factors, word length and structure of the final syllable, are considered in this study.) (3) Is the path of the change predictable?

\section{Background}

Previous studies on NK tones (G-R Kim 1988; Y-H Chung 1991; N-J Kim 1997; Kenstowicz and H-S Sohn 2001) reveal that there are two kinds of lexical accent in NK Korean: double high accent and single high accent. Words of the double high accent class have a high tone over the first two syllables, while those of the single high accent class have a high tone which falls on either the antepenultimate, penultimate, or final syllable. 
When foreign words are adopted into NK Korean, the accent and stress patterns from the source language are disregarded, and the loanwords are assigned a new accent. That is, they must be assigned one or two pitch peaks (high tone) just as in NK native words (e.g. lemón (LH) 'lemon', pisis (HL) 'bus', and rín.dín (HH) 'London'). The accents newly assigned to NK English loanwords seem to be similar to those of NK native words, but they actually show distinct characteristics and the difference is observed more clearly especially from the pattern of accentuation when certain suffixes are added.

NK Korean allows only one accent in a single prosodic word. Therefore, if an accented suffix is added to an accented stem, one of the underlying accents must be deleted. However, the deletion rule works differently in NK native words and in NK English loanwords. The following Table 1 and Table 2 show the tone patterns of NK native words and English loanwords with single high accent in three different conditions: in isolation, with an accentless nominative suffix $\left.-i / g a^{1}\right)$ and with an accented suffix $-t_{6}{ }^{h}$ 'ir $\wedge m$ (HL) 'like.' Since the suffixal accents differ between NK native words and English loanwords only for single high accent, this study will focus on the tone patterns of single high accented words. $\left.{ }^{2}\right)$ The different tone patterns between NK native words and NK English loanwords are marked in gray.

Table 1. Tone patterns of NK native words with accentless and accented suffixes

\begin{tabular}{|c|c|c|c|}
\hline \multirow{2}{*}{ NK native words } & \multirow{2}{*}{$\begin{array}{c}\text { (a) Monosyllabic } \\
\text { words }\end{array}$} & \multicolumn{2}{|c|}{ Disyllabic word } \\
\hline & & (b) Penultimate accent & (c) Final accent \\
\hline \multirow{3}{*}{ Stem word } & súl & pádak & parám \\
\hline & 'wine' & 'floor' & 'wind' \\
\hline & $\mathrm{H}$ & $\mathrm{HL}$ & LH \\
\hline Accentless suffix & súl-i & pádak-i & parám-i \\
\hline $\begin{array}{c}-i / g a \\
\text { (nominative) }\end{array}$ & $\mathrm{H}-\mathrm{L}$ & HL-L & LH-L \\
\hline $\begin{array}{c}\text { Accented suffix } \\
\text {-t6h'sım (HL) } \\
\text { 'like' }\end{array}$ & $\begin{array}{l}\text { sul-t.thisım } \\
\text { L-HL }\end{array}$ & $\begin{array}{c}\text { pádak-t. }{ }^{h} \Lambda{ } \wedge m \\
\text { HL-LL }\end{array}$ & $\begin{array}{c}\text { param-t6hiram } \\
\text { LL-HL }\end{array}$ \\
\hline
\end{tabular}

1) The shape of the nominative suffix $-i / g a$ is determined phonologically. Following a vowel, the suffix becomes -ga; and following a consonant, it is pronounced as - $i$ (I-S Lee and Ramsey 2000).

2) Since the second high tone of double high accent is considered unaccented (M Kim 1997), the underlying accent clash does not occur for double high accented words even when they are combined with an accented suffix. Therefore, double high accented words invariantly retain the stem accent. 
Table 2. Tone patterns of NK English loanwords with accentless and accented suffixes

\begin{tabular}{|c|c|c|c|}
\hline \multirow{2}{*}{$\begin{array}{l}\text { NK English } \\
\text { loanwords }\end{array}$} & \multirow{2}{*}{$\begin{array}{l}\text { (a) Monosyllabic } \\
\text { words }\end{array}$} & \multicolumn{2}{|c|}{ Disyllabic word } \\
\hline & & (b) Penultimate accent & (c) Final accent \\
\hline Stem word & $\begin{array}{l}k^{h \prime}{ }^{\prime} p \\
\text { 'cup' } \\
\mathrm{H}\end{array}$ & $\begin{array}{c}k^{h}{ }^{\prime} t_{6}^{h} \text { in } \\
\text { 'kitchen' } \\
\text { HL }\end{array}$ & $\begin{array}{l}k^{h} e t c^{h} a ́ p \\
\text { 'ketchap' } \\
\text { LH }\end{array}$ \\
\hline $\begin{array}{c}\text { Accentless suffix } \\
-i / g a \\
\text { (nominative) }\end{array}$ & $\begin{array}{l}k^{h} i^{\prime} p-i \\
\text { H-L }\end{array}$ & $\begin{array}{c}k^{h}{ }^{\prime} t_{6}^{h}{ }^{h} \text { n-i } \\
\text { HL-L }\end{array}$ & $\begin{array}{l}k^{h} e t c^{h} a ́ p-i \\
\text { LH-L }\end{array}$ \\
\hline $\begin{array}{c}\text { Accented suffix } \\
\text {-t6h'sım (HL) } \\
\text { 'like' }\end{array}$ & $\begin{array}{l}k^{h} \wedge p-t_{6}^{h} \Lambda{ }^{h} \wedge m \\
\text { H-LL }\end{array}$ & $\begin{array}{c}k^{h} i^{\prime}{ }^{h}{ }^{h}{ }^{\prime}-t_{6}{ }^{h} \wedge r a m \\
\text { HL-LL }\end{array}$ & $\begin{array}{c}k^{h} e t \sigma^{h a ́} p-t \sigma^{h}{ }^{\prime} \wedge r \Delta m \\
\text { LH-LL }\end{array}$ \\
\hline
\end{tabular}

For both NK native words and English loanwords, when a stem word is pronounced in isolation or is combined with an accentless suffix, there is only one underlying accent in a prosodic word, which is a stem accent. Therefore, the stem accent appears on the surface. Yet, if an accented suffix is attached to a stem, there are two underlying accents in a prosodic word, and thus one of the accents must be deleted.

Since nouns in NK Korean must have at least one accented syllable (G-R Kim 1988; Y-H Chung 1991; N-J Kim 1997), NK monosyllabic words are always realized with an accented high tone. When an accented suffix is attached to these words, the underlying accents of the stem and suffix are placed next to each other, and an accent clash occurs. In this case, NK native words and English loanwords exhibit distinct tone patterns as shown in (1a) and (2a): NK monosyllabic native words yield the accent to the suffix to alleviate the accent clash (i.e. $\mathrm{H}+\mathrm{HL} \rightarrow \mathrm{L}-\mathrm{HL}$ ), whereas NK monosyllabic English loanwords retain the accent on the stem (i.e. $\mathrm{H}+\mathrm{HL} \rightarrow \mathrm{H}-\mathrm{LL}$ ).

Unlike monosyllabic words, NK disyllabic words with single high accent exhibit two distinct tone patterns: penultimate accent and final accent. For words with penultimate accent, which appear in (1b) and (2b), the accent is on the initial syllable and the final syllable is unaccented having low tone. Therefore, there is no underlying accent clash between the stem and suffix even when an accented suffix is attached, and the stem accent survives in both NK native words and English loanwords. Yet, for disyllabic words with final accent, the accent is on the final syllable, and thus an underlying accent clash occurs when they are combined with an accented suffix. In this case, NK native words and NK English loanwords adopt 
different deletion rules as was seen in the monosyllabic words: NK native words delete the stem accent (i.e. $\mathrm{LH}+\mathrm{HL} \rightarrow \mathrm{LL}-\mathrm{HL}$, as shown in (1c)), while NK English loanwords delete the suffixal accent (i.e. LH $+\mathrm{HL} \rightarrow$ LH-LL, as shown in (2c)).

The tone patterns in Table 1 and Table 2 provide evidence that NK English loanwords have a strong tendency to retain their accent within the stem. This unique characteristic of English loanwords was reported by M Kim (1997) and examined further by Kenstowicz and H-S Sohn (2001). However, according to the authors' recent observations, this unique tendency of NK English loanwords seems to be changing especially among younger generations, and this change has not been reported in the previous literature.

\section{Expected Changes}

According to the previous literature such as M Kim (1997) and Kenstowicz \& Sohn (2001), NK English loanwords differentiate themselves from NK native words showing that they always retain their stem accent. However, the authors' recent observation through a pilot study with 3 younger and 3 older speakers of NK Korean revealed that the traditionally observed loanword tone patterns are disappearing and nativized patterns, which have not been previously reported, are observed. For instance, one of the examples Kenstowicz and H-S Sohn (2001) propose is kijaramél (LLH) 'caramel' plus an accented suffix - tcót $^{h}{ }^{h}$ (HL) 'even'. According to the traditional observation, the accent on the suffix must be deaccentuated as $k^{h j a r a m e ́ l-t 6 o t 6^{h} a}$ (LLH-LL). However, the results of the pilot study reveal that this word could be pronounced either with the accent on the stem or on the suffix. That is, both the stem accent $k^{h j a r a m e ́ l-\text { trot }^{h}}{ }^{h}$ (LLH-LL) and the suffixal accent $k^{h j a r a m e l-\text { t }_{\text {t }}{ }^{h} a}$ (LLL-HL) are acceptable and it seems that the latter one, the nativized pattern, is even more preferred by younger speakers. In addition to the generational difference, the nativized tone patterns seemed to be more frequently observed from longer words.

The following Table 3 shows how the newly observed suffixal tone patterns of NK English loanwords are different from those reported in the previous literature. Row (3a) shows final accented NK English loanwords in isolation, and (3b) shows their traditional tone patterns (stem accent) when they are combined with the accented suffix - $-t_{6}{ }^{h}$ 's $\wedge m$ (HL) 'like.' Row (3c) exhibits the nativized tone patterns newly observed from the pilot study. 
Table 3. Suffixal tone patterns of final accented NK English loanwords

\begin{tabular}{|c|c|c|c|}
\hline & 1 syllable & 2 syllables & 3 syllables and more \\
\hline (a) Stem word & $\begin{array}{l}k^{h} \wedge p \\
\text { 'cup' } \\
\mathrm{H}\end{array}$ & $\begin{array}{l}k^{h} e t c^{h} a ́ p \\
\text { 'ketchup' } \\
\text { LH }\end{array}$ & $\begin{array}{l}\text { alphabét } \\
\text { 'alphabet' } \\
\text { LLH }\end{array}$ \\
\hline $\begin{array}{l}\text { (b) Accented suffix } \\
-t^{h}{ }^{h} \wedge \mathrm{r} \wedge \text { (HL) 'like' } \\
\text { (previous literature) }\end{array}$ & $\begin{array}{c}k^{h} i p-t_{6}{ }^{h} \wedge r \Delta m \\
\text { H-LL } \\
\text { (stem accent) }\end{array}$ & $\begin{array}{l}k^{h} e^{h}{ }^{h} a ́ p-t c^{h} \wedge r \wedge m \\
\text { LH-LL } \\
\text { (stem accent) }\end{array}$ & $\begin{array}{l}\text { alphabét-tch }{ }^{h} \wedge \text { sm } \\
\text { LLH-LL } \\
\text { (stem accent) }\end{array}$ \\
\hline $\begin{array}{l}\text { (c) Accented suffix } \\
\text {-t6h'sım (HL) 'like' } \\
\text { (recent observation) }\end{array}$ & $\begin{array}{c}k^{h} i p-t 6^{h} \wedge r \Delta m \\
\text { H-LL } \\
\text { (stem accent) }\end{array}$ & 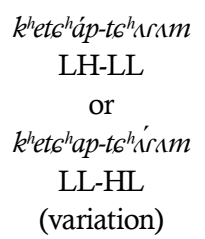 & $\begin{array}{l}\text { alp }{ }^{h} a b e ́ t-t 6^{h} \wedge r \wedge m \\
\text { LLH-LL } \\
\text { or } \\
\text { alphabet-t6h'sım } \\
\text { LLL-HL } \\
\text { (variation) }\end{array}$ \\
\hline
\end{tabular}

For monosyllabic English loanwords, the traditional pattern seems to be still mostly retained. However, for words with two or more syllables, some tone pattern change is happening especially among younger generations and nativized tone patterns are observed along with the traditional tone patterns. For instance, as seen in the examples in (3c), the disyllabic word khet6 ${ }^{h} a$ p (LH) 'ketchup' plus an accented

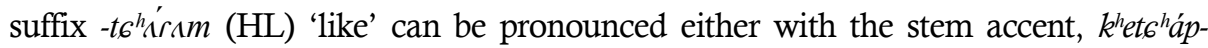
$t_{6}{ }^{h} \wedge \wedge m$ (LH-LL), or with the suffixal accent, $k^{h} e^{h}{ }^{h} a p-t 6^{h}{ }^{\prime}{ }^{\prime} \wedge m$ (LL-HL). Some speakers in the pilot study even reported that both the stem accent and the suffixal accent are equally acceptable according to their native intuitions. These newly observed nativized tone patterns appear more frequently on polysyllabic words. The results of the pilot study show that older speakers as well as younger speakers started exhibiting the nativized tone patterns for English loanwords with three or more syllables. However, the traditional loanword tone patterns were still observed quite frequently especially by older speakers. This variation differs from the traditional patterns reported in the previous literature (M Kim 1997; Kenstowicz and H-S Sohn 2001), which only indicates the stem accent. The difference between the previous literature and the authors' recent observations indicates that some tonal change might be in progress in NK English loanwords and motivates the current study. 


\section{Research Methods}

\subsection{Participants of production task}

Since one of the main purposes of this study is to examine the effects of age and gender on the degree of the tone pattern change, the current study includes two different generations of participants with the genders male and female. The younger group consisted of 13 native speakers of NK Korean in their 20s (five male (mean age $=22.8$, ranged from 20 to 25 ) and eight female (mean age $=25.7$, ranged from 21 to 28)), and the older group included 12 native speakers of NK Korean in their $50 \mathrm{~s}$ or $60 \mathrm{~s}$ (seven male (mean age $=59.2$, ranged from 57 to 64 ) and five female (mean age $=56.2$, ranged from 54 to 61 )). All participants were born and raised in the NK dialect region and none of them had lived in other dialect regions or outside of Korea for more than one year. They all had NK dialect-speaking parents who were born and raised in the NK region, and identified themselves as NK dialect speakers.

\subsection{Stimuli}

In order to investigate how the number of syllables and the structure of the final syllable affect the tone pattern change, the word stimuli in this study consisted of one-, two-, and three-syllable final accented NK native words and one-, two-, three-, and four-syllable final accented NK English loanwords that end with either a CV or CVC syllable structure. NK native words were included as a control group to verify the native tone patterns and to confirm that the tone pattern change is happening only in English loanwords. For English loanwords, four-syllable words ending in an open syllable were not included because these words are invariably assigned either double high accent or penultimate accent (Kenstowicz and H-S Sohn 2001). Four-syllable native words were not included as well because NK native words with four or more syllables are consistently assigned penultimate accent (Y-H Chung 1991; N-J Kim 1997). Both English loanwords and native words consist of high frequency words that would be familiar to the participants so that they would not be confused with the tone patterns. In total, English loanwords have seven, and native words have six categories with combinations of the syllable number and the structure of the final syllable. Three words were included in each category, and a total of 39 words were selected. The list of stimuli words is shown below in Table 4 . 
Table 4. Stimuli words (final-accented)

\begin{tabular}{|c|c|c|c|c|}
\hline & \multicolumn{2}{|c|}{ English loanwords } & \multicolumn{2}{|c|}{ Native words } \\
\hline & Final CV syllable & Final CVC syllable & Final CV syllable & Final CVC syllable \\
\hline 1-syllable & $\begin{array}{l}k^{h} a \text { 'car' } \\
t^{h i} \text { 'tea' } \\
\text { pa 'bar' }\end{array}$ & $\begin{array}{c}p^{h} \text { on 'phone' } \\
k^{h} \wedge p \text { 'cup' } \\
t^{h} \text { im 'team' }\end{array}$ & $\begin{array}{c}\text { mu 'daikon' } \\
\text { no 'paddle' } \\
\text { mo 'wool' }\end{array}$ & $\begin{array}{l}\text { t6oy 'bell' } \\
\text { sul 'liquor' } \\
\text { mal 'horse' }\end{array}$ \\
\hline 2-syllable & $\begin{array}{l}\text { si. } k^{h} i \text { 'ski' } \\
\text { si.tha 'star' } \\
k^{h} \text { a.re 'curry' }\end{array}$ & $\begin{array}{c}\text { le.mon 'lemon' } \\
\text { ki.rup 'group' } \\
k^{h} \text { e.t6hap 'ketchup' }\end{array}$ & $\begin{array}{c}\text { k'o.ma 'kid' } \\
\text { na.mu 'tree' } \\
\text { kon.bu 'study' }\end{array}$ & $\begin{array}{c}\text { Al.gul 'face' } \\
p^{h} a . r a \eta \quad \text { 'blue' } \\
\text { t'u.k'^y 'lid' }\end{array}$ \\
\hline 3-syllable & $\begin{array}{c}\text { sa.i.da } \\
\text { 'cider' } \\
\text { phi.a.no } \\
\text { 'piano' } \\
\text { pa.na.na } \\
\text { 'banana' }\end{array}$ & $\begin{array}{c}t_{6}^{h} \text { o. } k^{h} \text { ol.let } \\
\text { 'chocolate' } \\
\text { al.pha.bet } \\
\text { 'alpabet' } \\
\text { ri.mo.k } k^{h} \text { on } \\
\text { 'remote control' }\end{array}$ & $\begin{array}{l}\text { so.na.mu } \\
\text { 'pine tree' } \\
\text { tcin.dal.le } \\
\text { 'azalea' } \\
\text { te.na.mu } \\
\text { 'bamboo' }\end{array}$ & 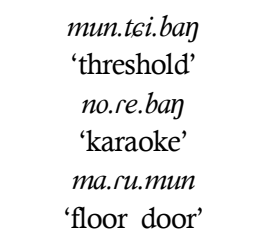 \\
\hline 4-syllable & N/A & $\begin{array}{c}p^{h i} \text { il.lay. } k^{h i} . t^{h} o n \\
\text { 'plankton' } \\
\text { pa.i.ol.lin } \\
\text { violin' } \\
p^{h} \text { i.ro.gi.ram } \\
\text { 'program' }\end{array}$ & N/A & N/A \\
\hline
\end{tabular}

In addition to these final accented words, one accentless suffix and two accented suffixes were selected to create two different accentual environments: where an accent clash occurs and where it does not. The following Table 5 shows the three suffixes used in this study.

Table 5. Suffixes

\begin{tabular}{ccc}
\hline Accent Type (tone pattern) & Suffix & Meaning \\
\hline \hline Accentless & $-i / g a$ & nominative \\
Accented (HL) & $-p o ́ . d a$ & more than \\
Accented (HL) & $-t^{h}$ hí $^{\prime}$ m & like \\
\hline
\end{tabular}

When the final accented words in Table 4 are combined with the accentless suffix $-i / g a$, no accent clash occurs. However, when the words are combined with one

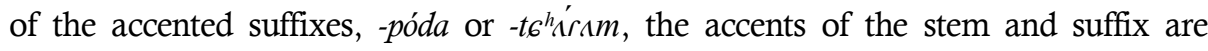
underlyingly placed next to each other, and one of the accents must be deleted. 


\subsection{Production task}

The combinations of the 39 final accented words and the three suffixes create 117 tokens. In order to attract natural production from participants, each token (a final accented word + a suffix) was provided in a sentence with a relevant adjective. For instance, a token with a combination of the word [phiano] 'piano' and the accented suffix [-po.da] 'more than' was combined with an adjective [ $\mathrm{k}^{\mathrm{h}} \mathrm{ida}$ ] 'big' to form a sentence: [ $\mathrm{p}^{\mathrm{h}}$ iano-poda-k ${ }^{\mathrm{h}} \mathrm{ida}$ ], piano-more than-big, 'It's bigger than a piano'. Then, all sentences were randomized in order and printed on paper in Korean. Participants were asked to read the provided sentences out loud naturally in NK Korean. Their productions were recorded in a quiet room with a Zoom $\mathrm{H} 4 \mathrm{nSP}$ digital voice recorder using the internal microphone. In total, 2,925 sentences were recorded (39 words $\times 3$ suffixes $\times 25$ participants).

\subsection{Annotation task}

After the production task, two younger (in their 20s) and two older (in their 50s) native speakers of NK Korean, who did not participate in the production task, listened to the recordings and annotated the tone patterns of each token to extract the data used for this study. Since both younger and older speakers were included for the production task, the annotation task also included both younger and older speakers. The annotators were instructed to listen to each sentence one by one and to choose whether the accent of each token is on the stem or on the suffix. In order for the participants (annotators) to be able to adjust themselves to the task, a practice set with 20 sample sentences was provided before the task. All four participants listened to 2,925 tokens (117 sentences produced by each of 25 speakers) and annotated the tone patterns. Due to the large number of production tokens for this study, the annotation task was divided into six sections. Each section contained around 500 sentences, and the participants were given a short break between the sections. All in all, each production token was annotated four times by different participants and in total 11,700 annotation responses were collected. Comparing the annotation results of each participant annotator, they had more than $93 \%$ agreement with one another, and all four annotators indicated the same tone pattern in more than $90 \%$ of the tokens. 


\section{Results}

\subsection{NK native words}

To check if NK native words are undergoing any kind of tone pattern change, 1,350 sentences were recorded and annotated by four annotators. In total, 5,400 annotation responses were collected. Among them, 1,800 are for the NK native words with the accentless nominative suffix $-i / g a$, and 3,600 are for those with the accented suffixes -póda 'more than' and -t6h'irsm 'like'.

Figures 1 and 2 below present the annotation responses for the native word tokens with each of the suffixes through a three-dimensional plot. It uses numbers (range from 0 to 4 ) and gradations of color to display the four annotation responses to each token. The horizontal axis represents each of the one-, two-, and three-syllable words that end with either a closed syllable or an open syllable. The vertical axis represents each participant of the four different age and gender groups. The older generation speakers are indicated in the top half of the figures and the younger generation speakers are indicated in the bottom half. The number and darkness of each cell represent the number of annotation responses that are different from the traditional tone patterns. For example, the number 0 means that none of the annotators annotated the token as a non-traditional pattern, and the number 4 means all four of the annotators indicated the token as a non-traditional tone pattern. Also, the more participants report non-traditional tone patterns in annotation, the darker the cell is. The number and darkness range from 0 (white) to 4 (black). Each plot exhibits the results of each suffix.

Fitst, Figure 1 presents the annotation responses for the NK native words with the accentless nominative suffix $-i / g a$. For the tokens with the accentless suffix $-i / g a$, very little variation was observed and there was no token that three or more participants annotated as a non-traditional tone pattern. Among the 1,800 annotation responses, 1796 (99.8\%) were annotated as stem accent. This shows that there is no noticeable tone pattern change happening in NK native words when they are combined with an accentless suffix.

However, unlike the results with the accentless suffix $-i / g a$, the annotation results

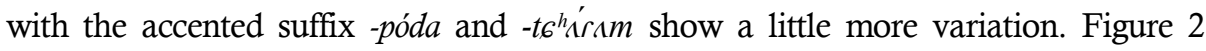
shows the annotation responses for each of the accented suffixes -póda 'more than' and $-t_{6}^{h}{ }^{h}$ ' $\wedge m$ 'like'. 


\begin{tabular}{|c|c|c|c|c|c|c|c|c|c|c|c|c|c|c|c|c|c|c|c|}
\hline \multicolumn{11}{|c|}{ Non-traditioanl tone pattern } & 0 & & 1 & & 2 & 3 & & 4 & \\
\hline \multicolumn{11}{|c|}{ Color } & & & & & & & & & \\
\hline \multicolumn{20}{|c|}{ Accentless suffix [-i/ga] 'nominative' } \\
\hline & & & \multicolumn{6}{|c|}{ 1-syllable } & \multicolumn{5}{|c|}{ 2-syllable } & \multicolumn{6}{|c|}{ 3-syllable } \\
\hline & & & \multicolumn{6}{|c|}{ closedi oper } & \multicolumn{3}{|c|}{ closed! } & \multicolumn{2}{|c|}{ open } & \multicolumn{3}{|c|}{ closed i } & \multicolumn{3}{|c|}{ open } \\
\hline \multirow{12}{*}{$\frac{\dot{\Phi}}{0}$} & & 1 & $\overline{0}$ & 0 & 01 & & & & 0 & & iं & 0 & 0 & 0 & 0 & 0 & 0 & $\overline{0}$ & \\
\hline & $\frac{0}{\pi}$ & $\frac{2}{2}$ & 0 & 0 & 01 & & ta & & 0 & & 10 & 0 & 0 & 0 & 0 & 01 & & 0 & \\
\hline & $\ddot{\Xi}$ & 3 & & 0 & $0 \mathrm{i}$ & & & & 0 & & $i_{0}$ & 0 & 0 & 0 & 0 & $0 \mathrm{i}$ & & 0 & \\
\hline & एँ & 4 & 0 & 0 & 0 & & tan & & 0 & 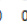 & 0 & 0 & 0 & 0 & 0 & 0 & & 0 & \\
\hline & & 5 & 0 & 0 & 01 & & 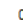 & & 0 & b & 10 & 0 & 0 & 0 & 0 & 01 & & 0 & \\
\hline & & 1 & 0 & 0 & $0 i$ & & & & 0 & & 10 & 0 & 0 & 0 & 0 & 01 & & 0 & \\
\hline & & $\frac{\pi}{2}$ & 0 & 0 & 0 & & 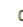 & & 0 & 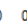 & 0 & 0 & 0 & 0 & 0 & 01 & & 0 & 0 \\
\hline & 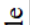 & 3 & 0 & 0 & 01 & & & & 0 & 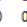 & 12 & 0 & 0 & 0 & 0 & 01 & & 0 & 0 \\
\hline & $\pi$ & $\frac{1}{4}$ & 0 & 0 & 01 & & 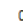 & & 0 & 0 & 10 & 0 & 0 & 0 & 0 & 01 & & 0 & 0 \\
\hline & $\Sigma$ & $\frac{7}{5}$ & 0 & 0 & 0 & & & & 0 & 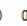 & 0 & 0 & 0 & 0 & 0 & 01 & 0 & 0 & 0 \\
\hline & & 6 & 0 & 0 & 01 & & & & 0 & 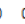 & 10 & 0 & 0 & 0 & 0 & 01 & & 0 & 0 \\
\hline & & & 0 & 0 & 01 & & & & 0 & b & 10 & 0 & 0 & 0 & 0 & 01 & & 0 & 0 \\
\hline \multirow{13}{*}{ 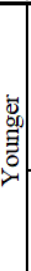 } & & 1 & 0 & 0 & 01 & & & & 0 & & 10 & $\overline{0}$ & 0 & 0 & $\overline{0}$ & 01 & & 0 & \\
\hline & & 2 & 0 & 0 & 01 & & 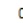 & & 0 & D & 10 & 0 & 0 & 0 & 0 & 01 & & 0 & 0 \\
\hline & (2) & 3 & 0 & 0 & 01 & & & & 0 & & 10 & 0 & 0 & 0 & 0 & 01 & & 0 & 0 \\
\hline & ]్త & 4 & 0 & 0 & 0 & & 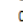 & & 0 & 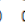 & 0 & 0 & 0 & 0 & 0 & 01 & & 0 & 0 \\
\hline & $\frac{7}{10}$ & 5 & 0 & 0 & 01 & 0 & 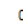 & & 0 & 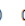 & 10 & 0 & 0 & 0 & 0 & 01 & & 0 & 0 \\
\hline & 红 & 6 & 0 & 0 & $0 i$ & & 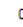 & & 0 & & $i_{0}$ & 0 & 0 & 0 & 0 & 01 & & 0 & 0 \\
\hline & & 7 & 0 & 0 & $0 !$ & & 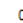 & & 0 & & 10 & 0 & 0 & 0 & 0 & 0 & & 0 & 0 \\
\hline & & 8 & 0 & 0 & 01 & & 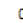 & & 0 & & 10 & 0 & 0 & 0 & 0 & 01 & & 0 & 0 \\
\hline & & 1 & 0 & 0 & 01 & & & & 0 & & 10 & 2 & 0 & 0 & 0 & $0 i$ & & 0 & 0 \\
\hline & (1) & 2 & 0 & 0 & 01 & & & & 0 & & 10 & 0 & 0 & 0 & 0 & 01 & & 0 & 0 \\
\hline & $\sqrt{\pi}$ & 3 & 0 & 0 & 01 & & 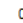 & & 0 & 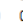 & 10 & 0 & 0 & 0 & 0 & 01 & & 0 & 0 \\
\hline & $\sum$ & 4 & 0 & 0 & & & & & 0 & & 10 & 0 & 0 & 0 & 0 & 01 & & 0 & 0 \\
\hline & & & 0 & 0 & & & & & 0 & & 10 & 0 & 0 & 0 & 0 & $0 !$ & & 0 & 0 \\
\hline
\end{tabular}

Figure 1. Annotation responses for native word tokens with the accentless suffix

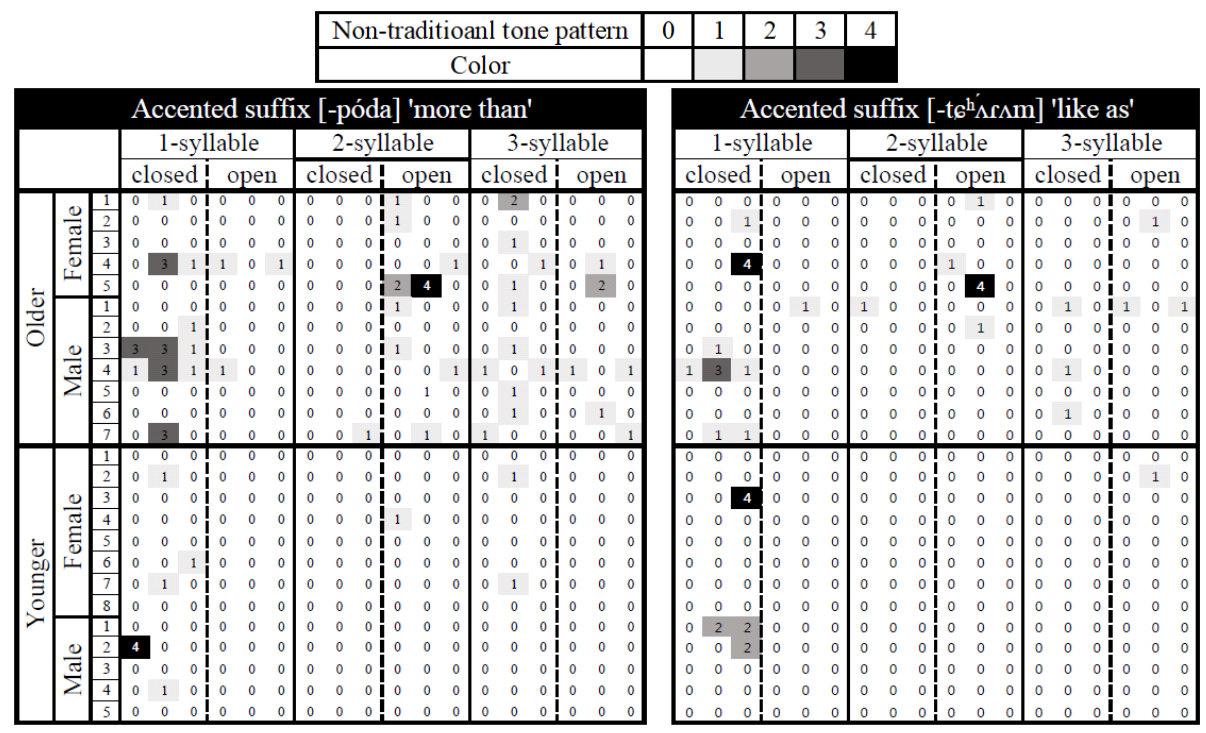

Figure 2. Annotation responses for native word tokens with the accented suffixes

Among each of the 1,800 annotation responses, 1,732 (96.2\%) of the accented suffix -póda 'more than' and 1,761 (97.8\%) of the accented suffix - $t_{6}{ }^{h}$ ' the traditional tone patterns (suffixal accent). In order to check if there is any social 
or linguistic factor that affects the variation, the annotation results were analyzed by running a poisson regression. The dependent variable was the annotation responses and the independent variables were age (older vs. younger), gender (male vs. female), the structure of the final syllable (open vs. closed), and the number of syllables (1-, 2-, 3-syllable). The statistical analysis of the data revealed main effects of age, the structure of the final syllable, and the number of syllables. The results show that the older speakers exhibit significantly more non-traditional tone patterns (stem accent) than the younger speakers $(p<.001)$, and the variation is more frequently observed from words with a final closed syllable than words with a final open syllable $(p=.001)$. For syllable numbers, 1-syllable words display more variation than 2-syllable and 3-syllable words $(p=.003)$, but there was no significant difference observed between 2-syllable and 3-syllable words. More detailed results are presented in Table 6.

Table 6. Results of the poisson regression for NK native words with accented suffixes

\begin{tabular}{|c|c|c|c|c|c|c|}
\hline \multirow{2}{*}{ Parameter } & & \multirow{2}{*}{ B } & \multirow{2}{*}{$\begin{array}{l}\text { Std. } \\
\text { Error }\end{array}$} & \multicolumn{2}{|c|}{$95 \%$ Wald CI } & \multirow{2}{*}{$P$} \\
\hline & & & & Lower & Upper & \\
\hline (Intercept) & & -1.646 & 0.2389 & -2.114 & -1.178 & 0.000 \\
\hline Age & Younger & -1.425 & 0.2421 & -1.900 & -0.951 & 0.000 \\
\hline Structure of final syllable & Open & -0.652 & 0.2028 & -1.049 & -0.254 & 0.001 \\
\hline \multirow{2}{*}{ Number of syllables } & 1 & 0.693 & 0.2315 & 0.240 & 1.147 & 0.003 \\
\hline & 2 & -0.154 & 0.2782 & -0.699 & 0.391 & 0.579 \\
\hline
\end{tabular}

Although the statistical results revealed that age, the structure of the final syllable, and the number of syllables are significant, the differences seem to be driven by annotation errors or speech errors. In both suffixes, less than $4 \%$ of the results exhibit the non-traditional patterns, and in most cases, only one of the four participants annotated the tone pattern differently. There were only 11 tokens that were annotated as a non-traditional tone pattern by three or more people, and most of them were found out to be speech errors. For instance, a single high accented word [mal] 'horse' should be pronounced with a suffixal accent (e.g. mál $(\mathrm{H})$ 'horse' +

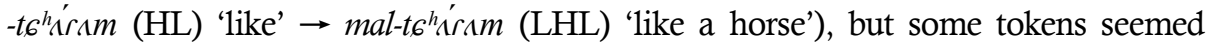
to be confused with its minimal pair, a double high accented word [ma:1] 'speech', and pronounced with a stem accent (e.g. má:l $(\mathrm{H})$ 'speech' + -t6h'sım (HL) 'like' $\rightarrow$ má:l-toh'śrım (HHL) 'like a speech').

In addition, for the observed difference between the two age groups, we could 
consider that a generational difference might exist regarding the location of the pitch peak. According to Lee and Jongman (2015), South Kyungsang Korean, another pitch-accent dialect spoken right next to the North Kyungsang dialect region, exhibits a generational difference for the location where a pitch peak occurs. They reveal that pitch peak is substantially delayed for younger speakers and is realized about a syllable later than older speakers. If similar change is also happening in North Kyungsang Korean, the suffixal accent might be more clearly perceived in speech of younger speakers, whereas it could be somewhat confused with the stem accent for speech of older speakers.

Overall, there was little variation observed in NK native words, and no noticeable tone pattern change was observed. Although some differences were observed between age group, structure of final syllable, and number of syllables, it seems that these can largely be attributed to annotation errors by the transcribers as well as speech errors by the speakers (especially with respect to the confusion regarding the word [mal] 'horse').

\subsection{NK English loanwords}

To check if any suffixal tone pattern change is happening on NK English loanwords, 1,575 production tokens were recorded and annotated by four participant annotators. In total, 6,300 annotation responses were collected. Among them, 2,100 are for the English loanwords with the accentless nominative suffix $-i / g a$, and 4,200 are for those with the accented suffixes -póda 'more than' and -t h $^{h}$ 's $\wedge m$ 'like'.

Figure 3 presents the 2,100 annotation responses with the accentless nominative suffix $-i / g a$. Among the 2,100 annotation responses, 2,095 (99.8\%) were annotated with the traditional loanword tone patterns, retaining the stem accent. Since there is no token that was annotated as a non-traditional tone pattern by three or more participants, all tokens can be considered to maintain the stem accent. This shows that there is no noticeable tone pattern change occurring in NK English loanwords when they are combined with an accentless suffix.

However, the traditional loanword patterns seem to be disappearing when the final accented English loanwords are combined with an accented suffix. Figure 4 presents the annotation responses of the English loanword tokens with the accented suffixes -póda 'more than' and -t ${ }^{h}{ }^{\prime}$ 's $\wedge m$ 'like'. (Recall that in the Figures the darker cells indicate the non-traditional loanword pattern with accent on the suffix rather than on the stem.) 


\begin{tabular}{|c|c|c|c|c|c|c|c|c|c|c|c|c|c|c|c|c|c|c|c|}
\hline & Non- & tra & aditi & oa & $\mathrm{nl} \mathrm{t}$ & ton & & patt & & & 0 & & 1 & & 2 & 3 & & 4 & \\
\hline & & & & & lor & & & & & & & & & & & & & & \\
\hline & & & Ac & $c$ & ntle & ess & & iffix & & & ]$^{\prime}$ & & mil & & & & & & \\
\hline & & & & syll & able & & & & syl & $a b$ & & & $3-s$ & $y l$ & labl & & & 4-syl & \\
\hline & & & close & & & jen & & close & & & pen & & close & & $\mathrm{op}$ & en & & losec & \\
\hline & & & & & & & 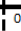 & 50 & & 0 & & 0 & 00 & & & & 0 & 0 & \\
\hline & & & & 0 & 0 & 00 & 10 & 0 & 0 & 0 & 0 & 10 & $0 \quad 0$ & 0 & 0 & & 10 & 0 & \\
\hline & & & 0 & 0 & 0 & 02 & & 0 & 0 & 0 & 00 & & 00 & 0 & 00 & 0 & 10 & 0 & \\
\hline & 4 & & 0 & 0 & 0 & $\begin{array}{ll}0 & 0 \\
0 & 0\end{array}$ & 0 & 0 & 0 & 0 & $\begin{array}{ll}0 & 0 \\
0 & 0\end{array}$ & & $\begin{array}{ll}00 \\
0\end{array}$ & 0 & 0 & 0 & & 0 & \\
\hline$\frac{\vec{d}}{\tau}$ & & 0 & 0 & 0 & & 0 & & 0 & 0 & 0 & 00 & 0 & 0 & $\begin{array}{l}0 \\
0\end{array}$ & & $\begin{array}{l}0 \\
0\end{array}$ & $\mid \begin{array}{l}0 \\
0\end{array}$ & & \\
\hline 0 & & & & 0 & 0 & 00 & Io & 0 & 0 & 0 & 0 & 10 & 00 & 0 & 0 & & 10 & 0 & \\
\hline & 93 & & 0 & 0 & 0 & & io & 0 & 0 & 0 & 0 & & 00 & 0 & 00 & & & 0 & \\
\hline & $\sqrt[\pi]{4}$ & & 0 & 0 & 0 & 00 & & 0 & 0 & 0 & 0 & & 00 & 0 & 0 & & & & \\
\hline & $\Sigma$ & & 0 & 0 & 0 & 00 & 10 & 0 & 0 & 0 & 0 & 10 & 0 & 0 & 0 & 0 & 10 & & \\
\hline & & & 0 & 0 & 0 & & & 0 & 0 & 0 & 0 & 10 & 0 & 0 & 0 & & & & \\
\hline & & & 0 & 0 & 0 & 0 & i。 & 0 & 0 & 0 & 0 & 10 & 0 & 0 & 0 & & 10 & 0 & \\
\hline & & & 0 & 0 & $\overline{0}$ & & $i 0$ & 50 & $\overline{0}$ & & $\overline{0}$ & ic & 00 & 0 & 0 & & 10 & 0 & \\
\hline & & & & 0 & 0 & & & 0 & 0 & 0 & 0 & & 00 & 0 & 0 & & & & \\
\hline & & & & 0 & 0 & & $i$ & 0 & 。 & 0 & 0 & 0 & 0 & 0 & 0 & 0 & 0 & & \\
\hline & ] & & 0 & 0 & 0 & $\begin{array}{ll}0 & 0\end{array}$ & Io & 0 & 0 & 0 & 0 & 10 & 00 & 0 & 0 & & 10 & 0 & \\
\hline & है & & 0 & & 0 & 00 & io & 0 & 0 & 0 & 0 & 10 & 00 & 0 & 0 & 00 & 10 & & \\
\hline & 56 & & & 0 & 0 & 00 & & 0 & 0 & 0 & 0 & & 00 & 1 & & 00 & & & \\
\hline & & 0 & 0 & 0 & 0 & 0 & 10 & 0 & 0 & 0 & 0 & 10 & 0 & 0 & 0 & 0 & 10 & 0 & 0 \\
\hline ప & & 0 & 0 & 0 & 0 & 0 & Io & 0 & 0 & 0 & 0 & io & 00 & 0 & 0 & 0 & & & \\
\hline$\lambda$ & & 0 & 0 & 0 & 0 & 0 & & 0 & 0 & 0 & 0 & & 00 & 0 & 0 & 0 & & & \\
\hline & $\stackrel{1}{1}$ & 0 & 0 & & & & & 0 & & 0 & 0 & & 0 & 0 & & 0 & & & \\
\hline & త్ & & 0 & 0 & 0 & & & 0 & 0 & & 0 & & 0 & 0 & 0 & 0 & & 0 & \\
\hline & $\Sigma$ & & 0 & & & & & 0 & 0 & & 0 & & 00 & 0 & 0 & & & & \\
\hline
\end{tabular}

Figure 3. Annotation responses for English loanword tokens with the accentless suffix

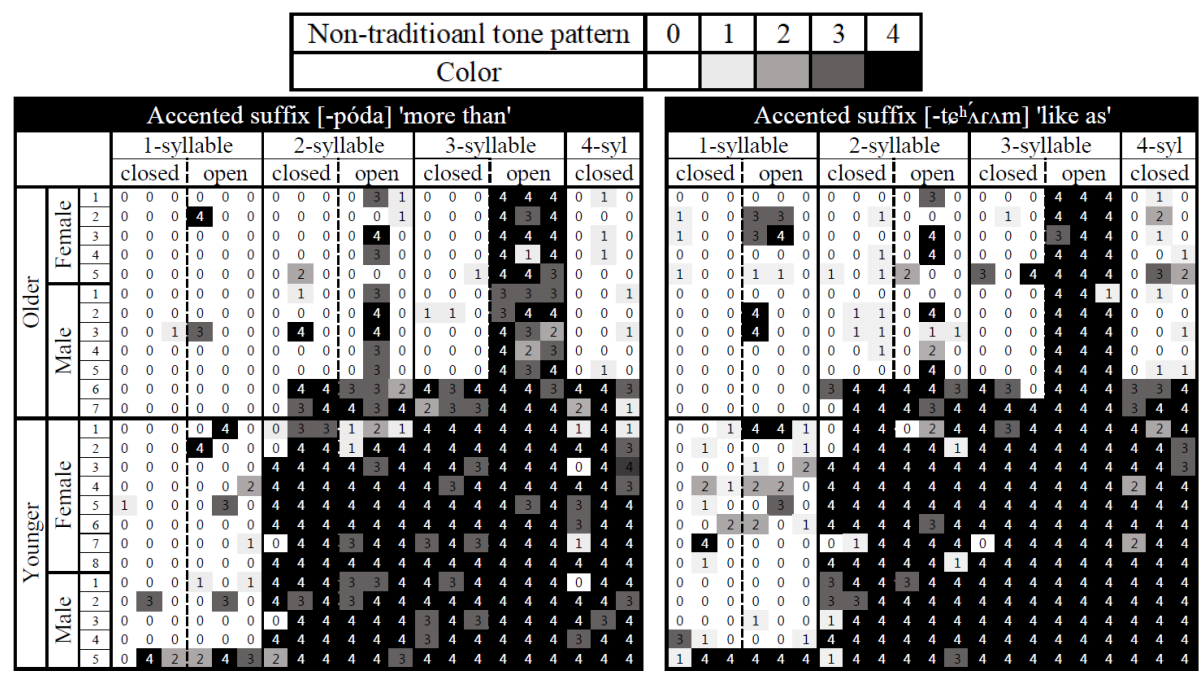

Figure 4. Annotation responses for English loanword tokens with the accented suffixes

Among each of the 2,100 annotation responses, 1,102 (52.5\%) of the accented suffix -póda 'more than' and 1,006 (47.9\%) of the accented suffix - $t_{6}^{h}{ }^{\text {' }}$ ' $\wedge m$ 'like' show the traditional loanword tone patterns (stem accent). The annotation results reveal that around half of the English loanword tokens have nativized their tone patterns 
having the accent on the suffix. This phenomenon indicates that some native-like tone pattern change is in progress in NK final accented English loanwords when they are combined with an accented suffix. In addition, the results of the accented

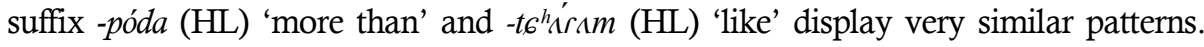
This means that the change is not limited to a certain suffix but is applied more generally with any accented suffix. Even though the change is slightly more advanced for the accented suffix - $t_{6}^{\text {h }}$ ' $\wedge$ $\wedge m$ 'like', the difference does not seem to be meaningful.

In order to examine which factor affects the change, we will discuss the results of each factor one by one. First, the annotation responses of both accented suffixes exhibit a clear difference between the two different age groups. Among the 2,100 annotation responses of each suffix, 1,008 were for the older speakers (21 words $\times 12$ speakers $\times 4$ annotations) and 1,092 were for the younger speakers (21 words $\times 13$ speakers $\times 4$ annotations). The results of the older speakers reveal that 757 (75.1\%) responses in the accented suffix -póda (HL) 'more than' and 705 (69.9\%) responses in the accented suffix - $-6^{h}{ }^{h}$ ' $\wedge m$ (HL) 'like' were annotated as the traditional tone patterns. For the results of the younger speakers, $345(31.6 \%)$ responses in the accented suffix -póda (HL) 'more than' and 301 (27.6\%) responses in the accented suffix $-t_{6}{ }^{h}$ ' $\wedge \mathrm{sm}$ (HL) 'like' were annotated as the traditional tone patterns. Both generations seem to be experiencing some change in their tone patterns, but the change is much more advanced for the younger generation. Although the older speakers still tend to maintain the traditional loanword tone patterns, the younger speakers have already lost their loanword specific tone patterns from most of the loanwords. This provides evidence that the native-like tone pattern change in NK English loanwords is being advanced by younger generations.

In addition, the number of syllables also seems to influence the degree of the tone pattern change happening in NK English loanwords. For both three-dimensional plots in Figure 4, the horizontal axis is divided by each of the one-, two-, three-, and four-syllable words. From the annotation results, we can notice that the rate of the traditional loanword tone patterns tends to decrease as the number of syllables increases and the change is quite patterned in both generations. First, for the younger generation, each of the one-, two-, three-syllable tokens have 312 annotation responses and the four-syllable tokens have 156 responses with both suffixes. The results of the younger speakers show that for each of the suffixes -póda and - $t_{6}{ }^{h}{ }^{\prime}{ }^{\prime} \wedge m$, $274(87.8 \%)$ and $249(79.8 \%)$ one-syllable tokens, $38(12.2 \%)$ and $39(12.5 \%)$ two-syllable tokens, $9(2.9 \%)$ and $5(1.6 \%)$ three-syllable tokens, and $24(15.4 \%)$ and 
$8(5.1 \%)$ four-syllable tokens retain the traditional loanword tone patterns with suffixal accent. The results indicate that the younger generation retains the traditional loanword tone patterns almost exclusively for the monosyllabic words. Although younger speakers keep the stem accent for more than $80 \%$ of the monosyllabic loanword tokens, the rate decreases dramatically for the words with two or more syllables. This shows that the loanword specific tone patterns have mostly disappeared from polysyllabic words in the production of the younger generation.

Although the change is not as advanced as the younger speakers, the older speakers are also experiencing the tone pattern change. For the older generation, each of the one-, two-, three-syllable tokens have 288 annotation responses and four-syllable tokens have 144 responses for both suffixes. For each suffix -póda and -t6 ${ }^{h}{ }^{\prime}{ }^{\prime} \mathrm{s} m, 280(97.2 \%)$ and $262(91 \%)$ monosyllabic, 218 (75.7\%) and $213(74 \%)$ bisyllabic, 139 (48.3\%) and 121 (42\%) trisyllabic, and 120 (83.3\%) and 109 (75.7\%) quadrisyllabic responses were considered to maintain the traditional loanword tone patterns. The results of the older speakers are somewhat similar with those of the younger speakers in that the change tends to be more advanced in polysyllabic loanwords. However, the degree of the change is quite different. Unlike the results of the younger speakers, the traditional loanword tone patterns are generally maintained for the older speakers, and the trisyllabic words are the only group that has lost the traditional loanword tone pattern from more than $50 \%$ of the tokens. However, even within the trisyllabic word group, the degree of change in the tone pattern is very different from one word to another, and this difference seems to be greatly influenced by the structure of the final syllable.

In Figure 4, the annotation results of each syllable, that is represented in the horizontal axis, are subdivided by the structure of the final syllable: Closed and Open. The results of both younger and older generations reveal that the tone pattern change is more advanced for words with a final open syllable. This invariantly applies to all the one-, two-, and three-syllable groups. However, the degree of the change is different for the two different generations. For the younger generation, the tone pattern change has mostly finished for the words with two or more syllables, while it seems to be just started for the monosyllabic words. Since most of the polysyllabic words already have the nativized tone pattern, relatively little difference was observed between the words with a final open syllable and those with a final closed syllable. Nevertheless, we could still observe that the change is a bit more advanced for the words with a final open syllable produced by the younger speakers. 
On the other hand, when it comes to the results of the older generation, the difference between the words with two different types of final syllable becomes very clear. For the older generation, the tone pattern seems to be very actively changing especially for the words that end with an open syllable, though each syllable group differs in the degree of the change. The change with loanwords ending in an open syllable is most complete for the trisyllabic words; most of them have already nativized their tone pattern. For bisyllabic words, the change is in progress, but the traditional pattern is still retained for more than $60 \%$ of the words with a final open syllable. The monosyllabic words seem to be at the very initial stage of the change, and a few words have started to nativize their tone pattern. That is, the traditional tone pattern is changing in every syllable group for words ending in an open syllable, though varying in degree. Yet, for the words ending with a closed syllable, the older speakers show little change in the tone pattern and no noticeable change is observed even in the quadrisyllabic words. From these results, we can assume that the change occurs first on words with a final open syllable, and in longer words before shorter words. This study also considered the gender difference as a social factor that might affect the degree of the tone pattern change, but we could not find any gender variation that generally applies.

In order to check the effect of the linguistic and social variables statistically, a poisson regression was conducted. The dependent variable was the annotation results and the independent variables were age (older vs. younger), gender (male vs. female), the structure of the final syllable (open vs. closed), and the number of syllables (1-, 2-, 3-, 4-syllable). The results confirmed that main effects of all independent variables were statistically significant. For the age difference, younger speakers are significantly more likely to nativize the tone pattern placing the accent on the suffix $(B=.968$, $p<.001)$. For the difference found in gender, male speakers show more evidence of the new pattern than female speakers $(B=.134, p=.003)$. The weight of the final syllable also has a significant effect on the accent change, and words with a final open syllable show more rating of the suffixal accent than words with a final closed syllable $(\mathrm{B}=.396, p<.001)$. For the effect of word length, the pattern appearing on the 1-syllable words is substantially different from the patterns appearing on other syllable words ( $\mathrm{B}=-1.832, p<.001)$. The pattern of 2-syllable words is also significantly different from that of 4-syllable words ( $\mathrm{B}=-.197, p=.006)$, but the difference is not as substantial as that of 1-syllable words. There was no significant difference observed between 3-syllable and 4-syllable words. More detailed statistical results are presented in Table 7 below. 
Table 7. Results of the poisson regression for NK loanwords with accented suffixes

\begin{tabular}{|c|c|c|c|c|c|c|}
\hline \multirow{2}{*}{ Parameter } & & \multirow{2}{*}{ B } & \multirow{2}{*}{$\begin{array}{l}\text { Std. } \\
\text { error }\end{array}$} & \multicolumn{2}{|c|}{ 95\% Wald CI } & \multirow{2}{*}{$\mathrm{P}$} \\
\hline & & & & Lower & Upper & \\
\hline \multicolumn{2}{|l|}{ (Intercept) } & 0.140 & 0.0709 & 0.001 & 0.279 & 0.048 \\
\hline Age & Younger & 0.968 & 0.0503 & 0.869 & 1.066 & 0.000 \\
\hline Gender & Male & 0.134 & 0.0445 & 0.047 & 0.221 & 0.003 \\
\hline Structure of final syllable & Open & 0.396 & 0.0487 & 0.301 & 0.492 & 0.000 \\
\hline \multirow{3}{*}{ Number of syllables } & 1 & -1.832 & 0.1059 & -2.039 & -1.624 & 0.000 \\
\hline & 2 & -0.197 & 0.0724 & -0.339 & -0.055 & 0.006 \\
\hline & 3 & 0.094 & 0.0698 & -0.043 & 0.231 & 0.178 \\
\hline
\end{tabular}

The results show that all the linguistic factors (structure of final syllable and number of syllables) and social factors (age and gender) have an influence on the degree of the tone pattern change occurring in NK English loanwords. The change is much more advanced for the younger generation and is patterned by the word length and structure of the final syllable. Although the statistical analysis revealed that the gender distinction also affects the change, it seems that the results of $\mathrm{OM}$ 6, 7 and YM 5 are driving this effect, rather than it being a gender effect.

\section{Summary and Discussion}

From the results, we can notice that a pitch-pattern diffusion is in progress across the board in final accented NK English loanwords when they are combined with an accented suffix. Such loanwords seem to be losing their traditional tone patterns (stem accent) and are becoming more like native words, having a suffixal accent. Although the diffusion is happening for both younger and older speakers, the degree of diffusion is different and is quite patterned, based on the word length and structure of the final syllable. For the younger speakers, most of the loanwords with two or more syllables have already nativized their tone patterns, whereas the diffusion is only beginning for monosyllabic loanwords, most of which keep their stem accent under suffixation. However, the older speakers mostly retain the traditional loanword tone patterns (stem accent) as described by M Kim (1997) and Kenstowicz and H-S Sohn (2001) except for two structurally defined group of words: bisyllabic and 
trisyllabic words that end with an accented light syllable. Between them, the change is much more advanced for the trisyllabic words. Here, we infer that the pitch-pattern diffusion witnessed by the younger generation began with trisyllabic words ending in final light syllables since this change is the one that is most advanced with the older generation.

Given the observations above regarding the similarities and differences between the two generations, we can plot the course for how the native-like pitch pattern diffusion is occurring on loanwords in NK Korean. For example, trisyllabic loanwords that end with a final open syllable show nativized tone patterns from both younger and older speakers. However, older speakers still tend to retain the traditional tone patterns for words with final closed syllable. Also, monosyllabic words produced by the younger speakers show that those consisting of a heavy syllable are most conservative in keeping the traditional loanword pattern of stem accent. Taken altogether, the results reflect that the change begins from polysyllabic loanwords with a final light syllable and ends with monosyllabic loanwords consisting of a final heavy syllable. That is, polysyllabic words are more affected by the diffusion, and within them, words that end with a light syllable change first.

Although in our study there was surprisingly little individual variation, we found one younger male speaker (YM5) whose pitch-pattern was nativized for all word categories. In his production, the diffusion was mostly done even for monosyllabic words that end with a heavy syllable. We also found two older male speakers (OM6, OM7) who have already nativized their suffixal tone patterns just like younger speakers. ${ }^{3)}$ The data presented here shows evidence for individual variation within this change, but in a predictable way. All in all, the results show that a pitch-pattern diffusion is in progress in NK English loanwords and it is a patterned diffusion. This supports Labov's (2012:290) contention of the "breathtaking uniformities" found in cases of in-progress community language change.

As a final matter, one can view the traditional difference in the resolution of accent clash in native words (suffixal accent wins) versus loanwords (stem accent wins) as emanating from a distinction in the domain of accent clash. This also could explain why loanwords with a final light syllable nativize their suffixal tone patterns first. In native words, only vowels can bear a mora (N-J Kim 1997; Y-H Chung 1998) and the accent clash domain is defined with respect to the syllable. If two accented syllables are next to each other, direct accent clash occurs between them.

3) It is interesting that these two males are not the youngest among the older speakers. They might interact more with younger speakers. 
However, in loanwords, both vowels and coda consonants can bear a mora (Kenstowicz and H-S Sohn 2001; Y-H Chung 1998, 2002; J-S Kim 2009), and the accent clash domain seems to be defined in terms of the mora. If a final accented word that ends with an open syllable, such as st.kit (LH) 'ski', is followed by an accented suffix, such as -t6h's $\mathrm{r} \wedge \mathrm{m}$ (HL) 'like', the two accented moras create a direct accent clash since there is no intervening mora between them. However, if a final accented word that ends with a closed syllable, such as lemón (LH) 'lemon', is combined with an accented suffix, it does not constitute a direct accent clash because there is an intervening mora (i.e. the coda-final $/ \mathrm{n} /$ of lemon would comprise a mora) between the two accented moras. It seems that the intervening mora alleviates the underlying accent clash and slows down the suffixal tone change in English loanwords that end with a heavy syllable.

In addition, the relative resistance of monosyllabic words to the change in progress may be due to a bimoraic minimal word requirement on loanwords. The accentuation of NK English loanwords is based on a bimoraic trochaic foot (Kenstowicz and H-S Sohn 2001; J-S Kim 2009; Y-H Chung 2002), and this might make the monosyllabic loanwords overtly or covertly bimoraic and thus more resistant to accent clash especially if the domain for loanword accent clash is moraic adjacency rather than syllable adjacency. We can also speculate that the suffixal tone change robustly occurring among younger speakers perhaps relates to the apparent loss of vowel length distinction by the younger generation (see H-J Kim 2018). Given that NK loanword phonology is mora-sensitive, the loss of the vowel length distinction might affect the entire loanword accentuation system. We leave these ideas as a basis for future research.

\section{Conclusion}

Language change that involves pitch often shows quicker transition compared to segment changes because there is no written form in the orthography indicating tone that would reinforce the conservative tendency. This paper has documented a patterned tonal change in progress involving suffixal forms of English loanwords in North Kyungsang Korean whereby the unique pattern of the preference for stem accent under clash resolution in loanwords is being lost in favor of the native pattern of suffixal accent. 


\section{References}

Chung, Young-Hee. (1991). Lexical tone of North Kyungsang Korean. Ph.D. dissertation. Ohio State University.

Chung, Young-Hee. (1998). Loanword tonal phonology of the North Kyungsang dialect of Korean: evidence for mismatches. Korean Journal of Linguistics 23, 709-722.

Chung, Young-Hee. (2002). Contextually-dependent weight of closed syllables: Cases of the North Kyungsang dialect and English. Eoneohag 33, 23-35.

Davis, Stuart. (2010). A note on the loanword tonology of Kyungsang Korean dialects. In S-O. Lee, ed., Contemporary Korean Linguistics: International Perspectives 46-62. Gyeonggi, Korea: Thaehaksa Publishing Co.

Jun, Jongho, Jungsun Kim, Hayoung Lee and Sun-Ah Jun. (2006). The prosodic structure and pitch accent of Northern Kyungsang Korean. Journal of East Asian Linguistics 15, 289-317.

Jun, Sun-Ah. (1998). The Accentual Phrase in the Korean prosodic hierarchy. Phonology 15(2), 189-226.

Jun, Sun-Ah. (2005). Korean intonational phonology and prosodic transcription. In S.-A. Jun, ed., Prosodic typology: The Phonology of Intonation and Phrasing, 201-229. New York: Oxford University Press.

Kenstowicz, Michael, Hyesun Cho and Jieun Kim. (2008). A note on contrasts, mergers and acquisitions in Kyungsang accents. Toronto Working Papers in Linguistics 28, 107-122.

Kenstowicz, Michael and Hyang-Sook Sohn. (2001). Accentual adaptation in North Kyungsang Korean. In M. Kenstowicz, ed., Ken Hale: A Life in Language, 239-270. Cambridge, MA: MIT Press.

Kim, Gyung-Ran. (1988). The Pitch Accent System of the Taegu Dialect of Korean with Emphasis on Tone Sandhi at the Phrasal Level. Ph.D dissertation. University of Hawaii.

Kim, Hyun-Ju. (2018). Diachronic change in vowel length contrast in North Kyungsang Korean. Studies in Phonetics, Phonology and Morphology 24(3), 273-295.

Kim, Jungsun. (2009). Double accent in loanwords of North Kyungsang Korean and variable syllable weight. Language Research 45(1), 67-83.

Kim, Michael. (1997). Korean monosyllables: Floating V-slot and edge bracket. In S. Kuno, I-H. Lee, J. Whitman, J. Maling, Y-S. Kang \& Y-J. Kim, eds., Harvard Studies in Korean Linguistics VII, 138-152. Cambridge, MA: Department of Linguistics, Harvard University. Kim, No-Ju. (1997). Tone, Segments, and Their Interaction in North Kyungsang Korean: A Correspondence Theoretic Account. Ph.D. dissertation. The Ohio State University.

Labov, William. (2012). What is to be learned: The community as the focus of social cognition. Review of Cognitive Linguistics 10, 265-293.

Lee, Hyunjung and Allard Jongman (2015). Acoustic evidence for diachronic sound change in Korean prosody: A comparative study of Seoul and South Kyungsang dialects. Journal of Phonetics 50, 15-33. 
Lee, Iksop and Robert S. Ramsey. (2000). The Korean Language. Albany: State University of New York Press.

Ramsey, Robert. (1975). Accent and Morphology in Korean Dialects: A Descriptive and Historical Study. Ph.D. dissertation. Yale University.

\author{
Young Hwang \\ Ph.D. Candidate \\ Department of Linguistics \\ Indiana University \\ 107 S Indiana Ave, Bloomington, IN 47405, USA \\ E-mail: hwang24@indiana.edu
}

\author{
Stuart Davis \\ Professor \\ Department of Linguistics \\ Indiana University \\ 107 S Indiana Ave, Bloomington, IN 47405, USA \\ E-mail: davis@indiana.edu
}

Received: February 21, 2019

Revised version received: April 9, 2019

Accepted: April 12, 2019 